\title{
SIGNIFICANCE OF USING HYDRAULIC OIL AS WORKING FLUID IN HYDRAULIC HYBRID VEHICLES
}

\author{
Chada Jithendra Sai Raja \\ Department of Mechanical engineering \\ Pragati engineering college, Surampalem, A.P, India
}

Dwarampudi Ramya Sudha

Department of Mechanical engineering

Pragati engineering college, Surampalem, A.P, India

\begin{abstract}
The consumption of fuel is increasing day to day which leads to the decrease in its content. Burning of fuel releases a huge amount of energy, we need to promote some environment friendly operations and regenerative systems where the consumption of natural resources is optimized there by restoring some quantity of energy released. Hydraulic hybrid system depends on oil based hydraulic fluid or water. In this research the properties of some hydraulic fluids and water are compared and the best fluid is introduced which increases efficiency for the same amount of fuel consumption and energy output may be increase. This results in optimum utilization of fuel. Thus reduces the global warming and pollution. And also increases the life of hydraulic hybrid system components.
\end{abstract}

Keywords - hybrid systems, hydraulic properties, regenerative braking, hydraulic oils

\section{INTRODUCTION}

Earlier the main source of transportation is animal power. Here we use animals like bull, horses, donkeys, etc. Slowly after civilization usage of animal power is reduced the drastic change took place after the invention of steam engines. Later hybrid vehicles came into progress. Though diesel engine is cheaper and versatile than petrol it exhausts harmful substances like $\mathrm{Co}, \mathrm{Co} 2$, etc causing many side effects to mankind like asthma, lung diseases, chronic heart and other. Henceforth research is made to encourage and develop advanced eco-friendly technology and operations. The use of renewable energy sources like wind, water, biomass instead of excessive usage of non-renewable sources like oil, natural gas, coal are stimulated. also the use of these sources causes increase in global warming and causes damage to health. The potential of water hydraulic technology in hydraulic hybrid system vehicle is implemented. Now a new idea of using a fluid with effective properties other than water is initiated. By

\author{
Mahboob Shaheen \\ Department of Mechanical engineering \\ Pragati engineering college, Surampalem, A.P, India
}

\author{
Vankala Nagababu \\ Department of Mechanical engineering \\ Pragati engineering college, Surampalem, A.P, India
}

this we can't reduce the use of non renewable energy sources but we can optimize the use.

\section{1 literature}

Hydraulic regenerative braking is an extensive advantage to hybrid system. The principle is "the hydraulic pump converts mechanical energy to fluid /hydraulic energy and the hydraulic motor coverts the high pressure of hydraulic energy to mechanical energy in order to drive the wheels. Accumulator increase efficiency and provides smoother, more reliable operation. The fuel consumption depends on number of accumulators used in hydraulic hybrid vehicle. The principle requirements for premium hydraulic working fluid is high viscosity index, good chemical stability, good oxidation stability, adequate pour point, resistance to foaming, high flash point.

\subsection{Methodology:}

In this study we gave a brief description of using hydraulic oils as working fluid in hydraulic hybrid vehicle. As we know hydraulic oils have higher boiling point compared to water. Using oil as a working fluid can also function as a lubricant. Hydraulic oil has chemical additives to improve the performance both the oil and components of hydraulic system. If the viscosity of fluid is high then the hydraulic component efficiency is low. In order to maximize efficiency we use low viscous hydraulic oils i.e. ISO VG2, ISO VG3, ISO VG5 etc.

\section{HYBRID SYSTEM VEHICLE:}

Heavy commercial vehicles that are in a stop and go mode produce large amount of energy in a moment. This gets wasted in the form of heat energy to the air stream i.e. $30 \%$ of vehicle's generated power is dissipated into the air. A hybrid vehicle uses more than one means of propulsion, which is combining a petrol or diesel engine with an electric motor or a 
pump. It uses pressurized fluid as a secondary source of energy.

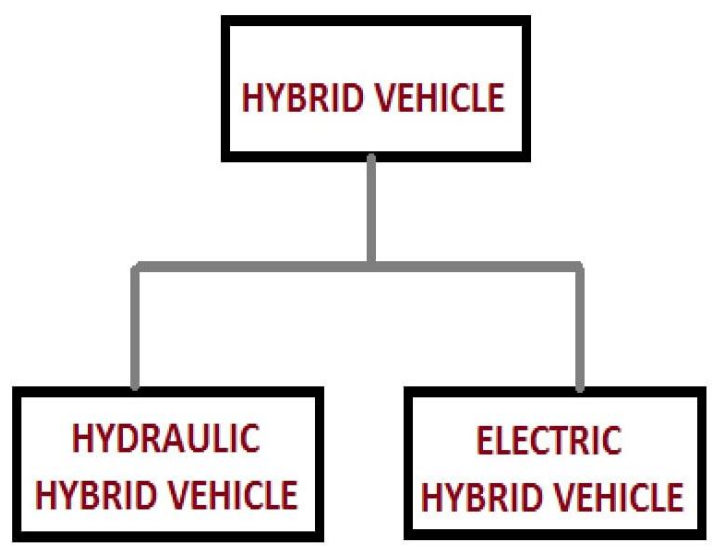

Fig :1

This hybrid system is of two types:

a) Electric hybrid vehicles

b) Hydraulic hybrid vehicles

\section{HYDRAULIC HYBRID VEHICLE:}

In this the hydraulic fluid is used as a secondary source of energy storage, and the energy is stored in the form of pressure.

On the basis of arrangement of components of the Hydraulic hybrid vehicle, it is classified into two types:

1. series hydraulic hybrid vehicle

2. parallel hydraulic hybrid vehicle.

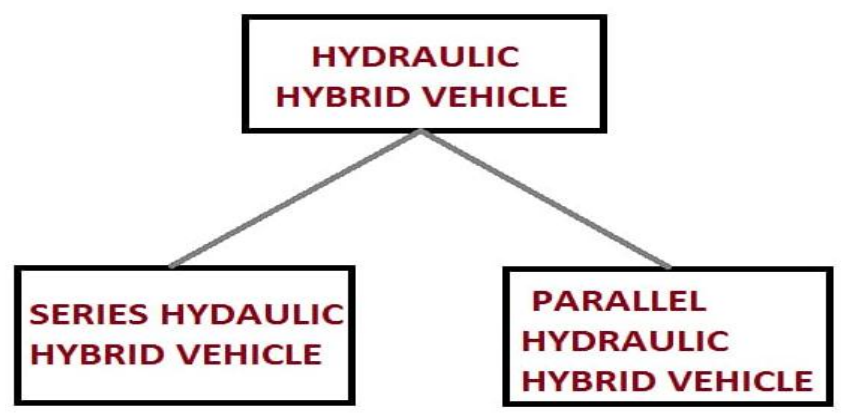

Fig:: 2

\section{PARALLEL HYDRAULIC HYBRID VEHICLE:}

Here the hydraulic components are connected to the conventional transmission and drive shaft.

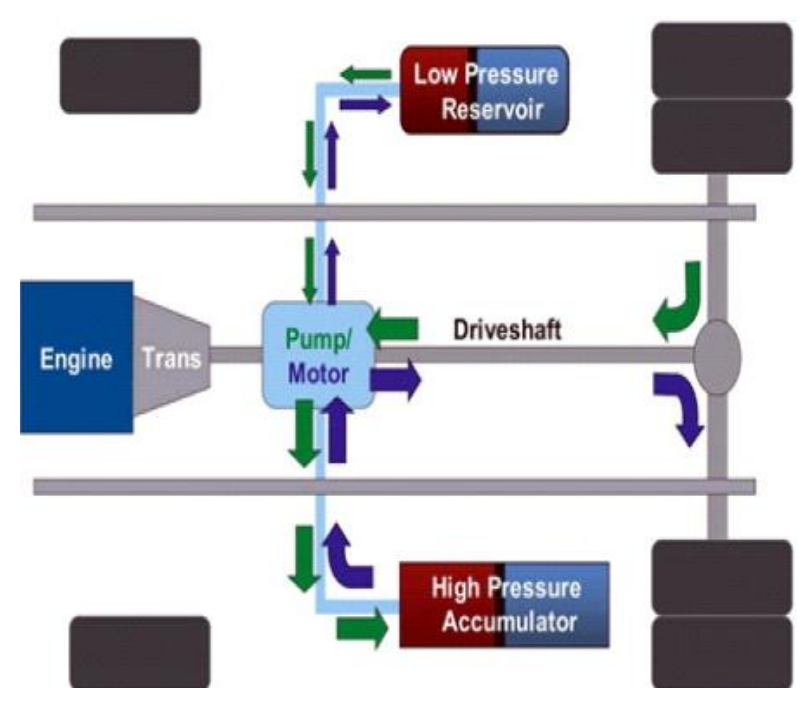

Fig.: 3

\section{SERIES HYDRAULIC HYBRID VEHICLE:}

It is same as parallel hydraulic hybrid vehicle but it doesn't utilize the conventional transition or driveshaft. The hydraulic system is one that transmits all power directly to the wheels.

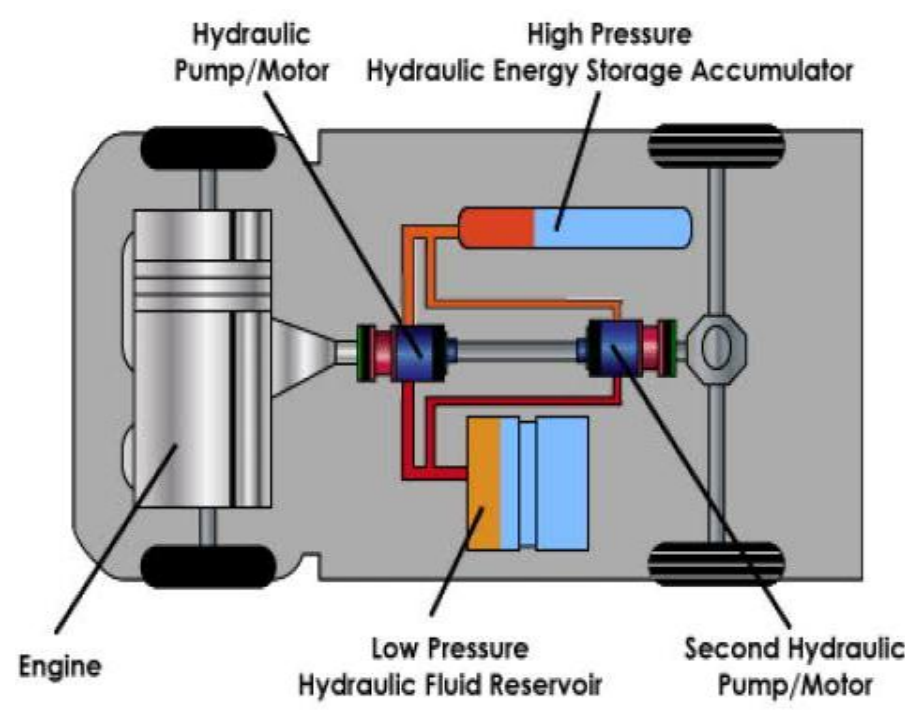

Fig: 4

\section{HYDRAULIC REGENERATIVE BRAKING SYSTEM:}

A hydraulic regenerative braking system mechanism stores a portion of kinetic energy that was a momentum as potential energy in the form of pressure. It is stored in a short term storage system by using a displacement pump to pump 
hydraulic fluid into a device called accumulator. This is released when needed as the vehicle accelerates. This pressure spins the drive shaft while the engine remains idle. As the vehicle achieves the desired speed and accumulator is emptied, the engine will continue to takeover process. Thus the optimum engine control made the hydraulic hybrid vehicle more efficient.

The hydraulic motor produces high torque even at zero speed. It can be attached directly to wheels so that the vehicle can be accelerated at zero speed. This will reduce the fuel consumption of engine. The hydraulic regenerative braking system increases the fuel efficiency of the vehicle.

\section{PRESSURE TANKS}

Energy is stored in hydraulic pressure tank that work by compressing an inert gas generally N2 separated from working fluid by membrane or a piston. Low pressure tank is called as a reservoir. High pressure tank is called as an accumulator. There are three types of hydro pneumatic accumulators:
a) Bladder type
b) Membrane type
c) Piston type.

\section{ADVANTAGES OF HYDRAULIC OILS OVER WATER}
a) Low temperature sensitivity of viscosity
b) Thermal and chemical stability
c) Good lubricant
d) Good coolant
e) Low pour point
f) High corrosion resistance property
g) Resistance to cavitations
h) Compatibility with sealant materials

\section{BASICS AND TERMINOLOGY OF HYDRAULIC OILS}

Hydraulic oil is the medium by which power is transmitted or transferred in hydraulic machinery. Most commonly used hydraulic oils are mineral oils and oil water emulsions. The classifications of hydraulic oils are as follows:

1. General hydraulic oils

2. Wear resistant hydraulic oils

3. Flame resistant hydraulic oils
a) Phosphoric acid ester based
b) Fatty acid ester based
c) Water glycol
d) Water oil emulsion type
e) Oil water emulsion type

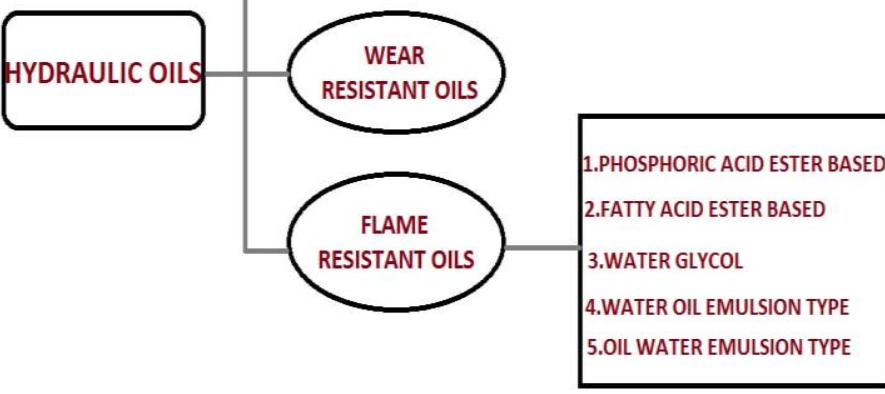

FIG:5

Based on the viscosity of hydraulic oils as the standard temperature of 40 degree Celsius international organization for standardization, the hydraulic oils are represented as

$$
\text { ISO } x
$$

Where, the $\mathrm{x}$ represents viscosity of hydraulic oil at 40 degree Celsius. Higher the grade numbers higher the viscosity of the oil.

\section{SIGNIFICANCE OF USING ISO VG5 \& ISSO VG 2:}

10.1. ISO VG5: It is a biodegradable mineral oil. It is formulated from high viscosity index solvent refined mineral based oil with additives to provide excellent protection against oxidation, corrosion, wear, and foaming.

a) Viscosity: it is a property by virtue of which the fluid offers resistance to the movement of one layer of fluid over the adjacent layer. It is due to cohesion and primary molecular momentum exchange between fluid layers. The viscosity of ISO VG5 at 40 degree Celsius is 4.8 centistokes and at 100 degree Celsius is 1.8 centistokes.

b) Density: Density of a fluid is a mass per fluid volume. The density of ISOVG 5 is $0.823 \mathrm{gm}$ per $\mathrm{ml}$.

c) Flash point: the flash point of hydraulic oil is the lowest temperature at which the oil vapors are ignitable. The flash point of IOS VG 5 is 171 degree Celsius

d) Pour point: the pour point of hydraulic oil is the lowest temperature at which the oil may flow. The pour point of ISO VG 5 is -21 degree Celsius.

\subsection{ISO VG 2:}

It can be used for both high speed and low speeds. These oils may also be implemented in some air powered tools. 


\section{International Journal of Engineering Applied Sciences and Technology, 2019 \\ Vol. 4, Issue 4, ISSN No. 2455-2143, Pages 115-118 \\ Published Online August 2019 in IJEAST (http://www.ijeast.com)}

a) Viscosity: the viscosity is 2.1 centisttokes at $40^{\circ} \mathrm{C}$ and 0.95 centistokes at $100^{\circ} \mathrm{C}$.the inter mediate viscosity is taken as 2.2 centistokes.

b) Density: the density is taken as $0.790 \mathrm{~g} / \mathrm{ml}$.

c) Flash point: the flash point is taken as $84^{\circ} \mathrm{C}$.

d) Pour point: the pour point is taken as $-36^{\circ} \mathrm{C}$.

\section{CONCLUSION}

In the hydraulic hybrid vehicle the use of water may cause cavitations, corrosion of accumulators and flowing pipes lubrication problem and thermal and chemical stability. This problem may be avoided by using hydraulic oil as we know they have high thermal and chemical stability, act as a good lubricant, high corrosion resistance property and resistance to cavitations. The use of hydraulic oil may cause in slightly increase of weight of the vehicle but it gives a good stability to the vehicle by placing the total weight concentration point nearer to the surface. It is more ecofriendly and cost advantage than electric hybrid vehicles. It produces high efficiency and high power density.

\section{FUTURE SCOPE}

We have a wide range of hydraulic oils with low viscosity i.e. ISO VG 2, ISO VG3 etc. But the flash point and pour point are very low that may cause a severe damage to the vehicle as well as we have the scope of increase in the flash point and the pour point or by decrease in the viscosity of the hydraulic oil.

\section{REFERENCE}

[1] Vjekoslav Tvrdic , Srdjan Podrug, Damir Jelaska and Milan Perkusic (2018), "Modal of hydraulic hybrid vehicle with regenerative suspensions" International Journal of Mechanical and Production Engineering, vol 6, issue 3(pgno:72-76).

[2] RohanHatti (2015), "hydraulic hybrid vehicle" , International Journal of engineering research and general science vol 3 ,issue 1 (pgno:85-90).

[3] "Evaluating the performance of hydraulic hybrid refuse vehicle " , National Renewable Energy Laboratory (sept 2015).

[4] R.M.Khavdu (2015), "regenerative braking system is emerging technology to recover waste energy, International Journal of Engineering Development and Research, vol 3, issue 4 (pgno: 1024-1028).

[5] ER. Amitesh Kumar (2012), "hydraulic regenerative braking system " , International Journal of scientific and engineering research, vol 3,issue 4 (pgno:1-12).

[6] https://en.wikipedia.org/wiki/Hydraulic hybrid_vehicle

[7] https://en.wikipedia.org/wiki/Hydraulic_fluids

[8] https://www.midlandslubricants.co.uk/agricultural/hydrauli c-oil/midlands-lubricants-hydraulic-oil-5/
[9] https://www.substech.com/dokuwiki/doku.php?id=hydrauli c oils

[10] https://www.google.com/search?q=iso+vg+5+oil\&oq=ais o+vg+5\&aqs=chrome.2.69i57j013.8742j0j7\&client=tabletandroid-telstra-au\&sourceid=chrome-mobile \&ie=UTF$\underline{8 \# \text { sbfbu }=1 \& \text { pi=iso } \% 20 \mathrm{vg} \% 205 \% 20 \text { oil }}$

[11]https://www.mobil.com/EnglishUS/Industrial/pds/GLXXMobil-Velocite-Oil-No-Series 